\section{Dinâmica do atendimento em planejamento familiar no Programa Saúde da Família no Brasil}

\author{
Family planning services under the Family \\ Health Program in Brazil
}

\footnotetext{
1 Faculdade de Farmácia, Odontologia e Enfermagem, Universidade Federal do Ceará, Fortaleza, Brasil. 2 Centro de Ciências da Saúde, Universidade de Fortaleza, Fortaleza, Brasil.

Correspondência E. R. F. Moura Departamento de Enfermagem, Faculdade de Farmácia, Odontologia e Enfermagem, Universidade Federal do Ceará. Rua Alexandre Baraúna 1115, Fortaleza, CE 60430-160, Brasil.

escolpaz@yahoo.com.br
}

\section{Abstract}

This evaluative study was performed in eight counties in Ceará State, Brazil, from July to September 2003. Data were collected through interviews with 29 nurses and 50 users of the Family Health Program (FHP), besides observations at health units. The aim was to identify the nature of family planning services and verify the existence of barriers to services and provision of contraceptives with a view towards ensuring an appropriate services network. Five styles of services were identified, although none followed a formal protocol, which raises a legal and ethical dilemma regarding prescription of contraceptives by nurses; delivery of contraceptive methods requires a monthly return visit by users due to excessive and unnecessary technical requirements that create barriers to access by users; and there is a lack of appropriate services, with nurse- and doctor-centered treatment and lack of partnership with other reproductive health services or community groups. Future studies should be designed to identify distinct dynamics in the FHP that innovate in family planning, as well as to define the legal and ethical framework for nurses to prescribe the methods.

Family Planning (Public Health); Contraception; Family Health Program
Escolástica Rejane Ferreira Moura 1

Raimunda Magalhães da Silva 2

Marli Teresinha Gimeniz Galvão 1

\section{Introdução}

A assistência ao planejamento familiar é oferecida, atualmente, no Brasil, pelas equipes do Programa Saúde da Família (PSF), um modelo de política pública de saúde que traz a proposta do trabalho em equipe, de vinculação dos profissionais com a comunidade e de valorização e incentivo à participação comunitária. Corresponde a uma das sete áreas prioritárias de intervenção na atenção básica, definidas na Norma Operacional da Assistência 1 .

O PSF tem o propósito de reverter a forma de oferta da assistência à saúde, ou seja, incorporando ações coletivas de cunho promocional e preventivo a substituir progressivamente o atendimento individualizado, curativo, de alto custo e de baixo impacto. Neste aspecto, é imprescindível o estabelecimento de parcerias intersetoriais com educação, ação social, trabalho, outras instâncias governamentais e a sociedade civil 2. No Estado do Ceará, Brasil, o PSF teve implantação iniciada em 1994, oferecendo cobertura de $56 \%$ da população no período deste estudo, com equipes atuando nos seus 184 municípios ${ }^{3}$.

As equipes do PSF são constituídas por um médico, um enfermeiro, um auxiliar de enfermagem e seis agentes comunitários de saúde (ACS), co-responsáveis pela saúde de cerca de mil famílias, o que corresponde à média de 3.450 a 4.500 pessoas 2 . 
O Ministério da Saúde (MS), tomando por base o dispositivo da lei do planejamento familiar (Lei $n^{o}$. 9.263/96), determina, como competência dos profissionais de saúde, assistir em concepção e contracepção, empenhando-se em informar os indivíduos sobre as opções para as duas finalidades, destacando a oferta dos métodos anticoncepcionais autorizados e disponíveis no Brasil - Billings, tabela, temperatura, sintotérmico, camisinha masculina e feminina, diafragma, espermicida, dispositivo intra-uterino (DIU), hormonais orais e injetáveis, laqueadura e vasectomia 4 .

Apesar das condições mencionadas, negligências ocorrem nos serviços de atenção ao planejamento familiar, quando maior ênfase é dada à contracepção, permitindo o desenvolvimento de uma política controladora, na qual a mulher exerce um papel muito mais de objeto do que de sujeito da sua história sexual e reprodutiva; a variedade de métodos anticoncepcionais é limitada e sua provisão irregular; e não há definição de papéis dos profissionais que compõem a equipe, percebendo-se, pois, uma distância entre o que está proposto na política do MS e o que é prática no PSF.

Uma estrutura simples para avaliar serviços de planejamento familiar foi proposta por Bruce 5, estabelecendo seis elementos que norteiam a qualidade nessa área: oferta e livre escolha dos métodos anticoncepcionais; informação dada ao cliente; competência técnica profissional; relacionamento interpessoal profissionalcliente; acompanhamento dos usuários; e rede apropriada de serviços, sendo a avaliação deste último o objeto deste estudo.

Para responder às expectativas dos clientes e facilitar seu acesso, uma rede apropriada de serviços de planejamento familiar deve estar disponível, e que seja conveniente e aceitável. O atendimento há de estar próximo de onde as pessoas vivem, promover a autonomia dos usuários e entregar os métodos de forma descentralizada. Portanto, às equipes de PSF compete estabelecer integração com os serviços de pós-parto, de pósaborto, de prevenção do câncer de colo uterino, de controle das doenças sexualmente transmissíveis, pois, tendo nas mulheres em idade reprodutiva sua clientela-alvo, ensejarão oportunidades para expandir a rede de atendimento e otimizar o contato da usuária com a equipe de saúde.

Sistemas baseados em comunidades, envolvimento de pontos comerciais e operações nos próprios serviços de saúde que incentivem o retorno das usuárias de métodos anticoncepcionais para um fornecimento de contraceptivo com fácil acesso, são relevantes para o alcance do objetivo geral de continuidade de uso dos méto- dos anticoncepcionais. $\mathrm{O}$ acompanhamento não termina no primeiro atendimento, porém muitos serviços de planejamento familiar são projetados mais ao recrutamento dos clientes do que na manutenção do uso de métodos 5 .

Um aspecto da avaliação de uma dinâmica de atendimento em planejamento familiar inclui o julgamento quanto a fornecer ou não assistência e métodos anticoncepcionais adequadamente $\mathrm{e}$ dentro do espaço articulado do Programa (área adstrita do PSF, por exemplo); o segundo nível do julgamento é saber se a rede de serviços está apropriada às necessidades e anseios da população. Enfim, uma rede apropriada de serviços é o que se espera no sentido de oferecer às mulheres, homens ou casais, fácil acesso aos métodos anticoncepcionais, por meio da descentralização e variedade de pontos de entrega, reduzindo a descontinuidade de uso do método anticoncepcional porque a usuária não teve como recebê-lo 5 .

Com base no exposto, perguntou-se: qual a dinâmica de atendimento em planejamento familiar adotada pelas equipes de PSF? Mostra-se coerente à expectativa dos usuários? Os serviços são ofertados na perspectiva de uma rede apropriada de serviços? Assim, o presente estudo teve por objetivos avaliar a dinâmica do atendimento em planejamento familiar desenvolvida por equipes de PSF e verificar a existência de barreiras no atendimento e entrega de métodos anticoncepcionais, na perspectiva de uma rede apropriada de serviços.

\section{Metodologia}

Pesquisa avaliativa com o propósito de averiguar a dinâmica do serviço de planejamento familiar, na perspectiva de se encontrar respostas para as questões práticas do cotidiano. García-Núñes 6 reforça esse raciocínio, ao enfatizar a idéia de que a avaliação em planejamento familiar mostra aquilo que funciona e o que não funciona, o que se deve manter ou mudar, constituindo um instrumento para a tomada de decisão.

O estudo foi realizado nos municípios cearenses que compõem a 4a Célula Regional de Saúde (CERES) - Aratuba, Mulungu, Guaramiranga, Pacoti, Baturité, Itapiúna, Capistrano e Aracoiaba, de julho a setembro de 2003, incluindo áreas urbanas e rurais. A Célula possui 122.933 habitantes, dos quais 30.345 são mulheres em idade fértil (15 a 49 anos) e, no período do estudo, contava com 30.116 famílias cadastradas no PSF, o correspondente a $87,84 \%$ de cobertura ${ }^{3}$. CERES é o resultado do processo de regionalização do sistema de saúde do Ceará, sendo definida como um espaço geográfico e populacional composto 
por um conjunto de municípios agrupados por afinidades culturais, econômicas e de prestação de serviços, cuja articulação visa à busca de soluções para problemas comuns na área da saúde, com vistas a oferecer uma assistência integral em uma rede apropriada de serviços. Funciona, ainda, como organização virtual de pactuação e negociação, sustentada por uma Comissão Intergestora Bipartite (CIB) que origina instrumentos de planejamento com base na Programação Pactuada Integrada (PPI) 7 .

Foram entrevistados 29 enfermeiros (90,6\% do total de enfermeiros de PSF da CERES), selecionados pelo critério de atuar no PSF e atender em planejamento familiar, aos quais se indagou: quem realiza o atendimento e a entrega dos métodos anticoncepcionais na sua equipe? Para onde são encaminhadas as usuárias cujas escolhas não estão disponíveis localmente? O número de usuários foi delimitado pela saturação das falas, ou seja, a coleta de dados foi iniciada sem predeterminação do número de participantes e, quando ocorreu a dominância de repetição das informações, a amostra foi considerada adequada e encerrada com cinqüenta respondentes, escolhidos pelo critério de ser usuário do serviço de planejamento familiar no PSF 8. À estas se perguntou como avaliavam a forma de atendimento em planejamento familiar e de entrega dos métodos anticoncepcionais. Para Cruz Neto 9, a entrevista proporciona a obtenção de informes contidos nas falas dos participantes, tanto de cunho objetivo quanto de teor subjetivo.

Também se utilizou a observação livre, cujos dados foram registrados em diário de campo, conduzindo a conhecer os atos, a dinâmica espontânea dos profissionais e usuários, sua prática e seu cotidiano, possibilitando levantar mais detalhes sobre o objeto investigado 10 .

As falas das usuárias e dos enfermeiros foram organizadas conforme a técnica de análise categorial proposta por Bardin 11, incluindo as fases de pré-análise, exploração do material e interpretação. Na pré-análise, os dados foram organizados pela lógica, intuição e conhecimentos acumulados das autoras. Idéias iniciais foram sistematizadas, ao se fazer repetidas leituras dos conteúdos, identificando semelhanças e divergências, permitindo agrupar os dados por temáticas oriundas de sentimentos ou ações expressas pelos sujeitos.

Na fase da exploração do material, os roteiros das entrevistas das usuárias foram numerados de 1 a 50 e dos enfermeiros de 1 a 29. As informações fornecidas pelos enfermeiros foram codificadas por E, enquanto aquelas relatadas pelas usuárias foram codificadas por U. Realizou-se leitura fragmentada de todo o material, com a intenção de reuni-lo em unidades de significados convergentes e divergentes. Assim, os resultados foram apresentados nas categorias: dinâmica de atendimento em planejamento familiar adotada pelas equipes de PSF; barreiras do atendimento/ entrega dos métodos anticoncepcionais; e rede de serviço de planejamento familiar. Na interpretação, os resultados brutos foram tratados à luz da literatura atual e experiência acumulada das autoras.

O estudo seguiu as recomendações da Resolução no. 196/96, do Conselho Nacional de Saúde, que trata das diretrizes e normas regulamentadoras de pesquisas envolvendo seres humanos. Foi submetido ao Comitê de Ética em Pesquisa do Complexo Hospitalar da Universidade Federal do Ceará, obtendo parecer favorável.

\section{Resultados}

\section{Dinâmica do atendimento \\ em planejamento familiar no PSF}

A dinâmica de atendimento e de entrega dos métodos anticoncepcionais variou de equipe para equipe, inclusive no mesmo município, não sendo observada uma padronização ou rotina formal de atendimento a ser seguida de maneira sistemática pelas equipes de PSF. A prescrição e a entrega dos métodos anticoncepcionais mantêm-se atreladas a barreiras institucionais e profissionais, como a preocupação para que o médico realize toda primeira consulta de planejamento familiar, prescreva os hormonais orais e injetáveis, insira o DIU e atenda aos adolescentes.

Foi possível identificar, pois, as seguintes dinâmicas de atendimento: (1) prescrição dos métodos anticoncepcionais por enfermeiros em 14 (48,3\%) equipes; em uma destas equipes, clientes de primeiro atendimento e adolescentes eram encaminhadas para o médico; (2) prescrição da maioria dos métodos anticoncepcionais por enfermeiros, exceto o injetável, em 5 (17,2\%) equipes; (3) prescrição dos métodos anticoncepcionais por enfermeiros, à exceção do injetável e do anovulatório oral, em 4 (13,8\%) equipes; (4) prescrição dos métodos anticoncepcionais somente pelo médico em 4 (13,8\%) das equipes; e (5) entrega dos métodos anticoncepcionais por enfermeiros que não realizavam a prescrição formalmente por temerem denúncia em 2 (6,9\%) equipes.

Os quatro enfermeiros que não prescreviam contavam com o médico na equipe realizando tal atribuição. Nesta dinâmica, o enfermeiro mantinha o acompanhamento dos retornos e assegu- 
rava a interconsulta enfermeiro-médico, quando necessário.

$\mathrm{O}$ auxiliar de enfermagem recepciona a clientela e, em algumas equipes, verifica o peso e a pressão arterial em sistema de pré-consulta. $\mathrm{O}$ ACS atua como um interlocutor entre a equipe de saúde e os usuários, informando-os sobre os dias e os horários de atendimento em planejamento familiar e sobre os métodos anticoncepcionais disponíveis. Por ocasião das visitas domiciliárias, orientam sobre aspectos básicos do planejamento familiar e dos métodos anticoncepcionais.

Parte dos enfermeiros que prescrevia os métodos anticoncepcionais atribuiu o fato à inexistência de médico na equipe, expressando:

"Passei dois meses sem médico na equipe e prescrevi, pois a paciente só recebe a pílula, por exemplo, se deixar a receita na Farmácia" (E15).

"Quando tem médico só atendo os retornos" (E16).

"Não tem médico na equipe para prescrever o método. Tento encaminhar para o médico do hospital municipal, mas as mulheres não querem ir" (E2, E4).

A rotatividade dos médicos nas equipes é freqüente, ficando longos períodos sem substituição. "Eles mudam demais e quando a mulher vem para o atendimento, ela quer receber o método de qualquer jeito ..." (E5). Esse aspecto foi reforçado na voz da usuária, que ressaltou: "Eles [os médicos] deviam durar mais. Não dá nem tempo a gente se acostumar com eles, já vem outros" (U19).

Outro aspecto é que boa parte dos médicos não dedica tempo integral ao PSF: “O médico só atende duas vezes na semana, o resto eu fico sozinha; é terrivel", afirmou E18.

Outros enfermeiros, apesar de contarem com médico na equipe, prescreviam os métodos anticoncepcionais, argumentando o pouco envolvimento médico nas ações de planejamento familiar. Os depoimentos apresentados a seguir demonstram essa posição:

“O médico só participa do DIU” (E4).

"O médico não se interessa pelo planejamento familiar, deixa só com a enfermeira” (E5).

"Tem que ter a participação do médico. Eles querem que o planejamento familiar fique só com a enfermeira" (E6).

"Quando a mulher vai ao médico ele diz que isso não é com ele, que a mulher procure a enfermeira" (E7).

"Nós preenchemos esse espaço todo do planejamento familiar. Quando encaminhamos a paciente para os médicos eles devolvem pra gente" (E8).

Uma enfermeira declarou realizar todas as atividades da assistência ao planejamento fa- miliar, pois se avalia como bem preparada para a tarefa, ao tempo em que verbalizou: "No caso da pílula combinada, por exemplo, uma paciente hipertensa grave e com mais de 40 anos veio do médico com a receita [nesta situação, segundo critério de elegibilidade clínica da Organização Mundial da Saúde - OMS - este seria o método de última escolha]. Então este e outros casos me fizeram tomar a decisão de que todo planejamento familiar na minha área fosse feito por mim" (E27). Outra expressou que "as mulheres já chegam na unidade de saúde sabendo que o atendimento em planejamento familiar é com a enfermeira" (E8), o que faz pensar ser uma ação realizada predominantemente pelo enfermeiro, o que se confirma em observação registrada em diário de campo: "Como é que a gente tira comprimido aqui?" [indagou uma mulher da comunidade]. A funcionária respondeu: "É se consultando com a enfermeira (...) é só vir nas quintas-feiras”.

\section{Barreiras no atendimento/ entrega dos métodos anticoncepcionais}

Retornar mensalmente à unidade básica de saúde para receber o método anticoncepcional foi dificuldade apresentada por 17 (34\%) das mulheres; e a longa espera foi queixa de outras 11 $(22 \%)$. As demais usuárias ouvidas, ou seja, 22 (44\%) mostraram-se satisfeitas com a dinâmica de atendimento e entrega dos métodos.

Os depoimentos das usuárias insatisfeitas foram verdadeiros apelos para que as equipes ampliassem o intervalo de entrega dos anticoncepcionais:

"Vir todo mês só pegar uma cartela de comprimido é demais num é não? É horrível todo mês vir pra levar" (U29, U30).

"Vir todo mês à unidade de saúde é horrível, caminho meia hora a pé" (U47).

"Se eu recebesse duas ou três caixas seria melhor" (U28).

"Estudo e sou dona de casa. Vir todo mês é ruim” (U31).

“... Eu pego ônibus pra chegar na unidade” (U42).

Sobre tais reivindicações, 20 (69\%) enfermeiros mostraram-se radicalmente contrários, inclusive discordando da participação do auxiliar de enfermagem e do ACS nessa tarefa. Estes defenderam a presença mensal das clientes ao serviço de saúde com argumentos excedentes e desnecessários, como: o temor de que a usuária apresente dúvidas, efeitos colaterais e/ou complicações; o método falhar; necessidade de verificar peso e pressão arterial das usuárias mensalmente; e a usuária receber influência negativa da comunidade quanto ao método. 
"Não acho correto, pois vem dúvida, queixa, complicação e o agente de saúde e o auxiliar de enfermagem não fazem como a gente" (E15).

"Receio de efeitos colaterais que a gente não esteja observando corretamente" (E21).

"Tem que todas receber comigo" (E28).

"É muito errada a entrega pelo agente de saúde. Não mando de jeito nenhum, jamais" (E5, E17, E22).

"Morro de medo, não confio, já peguei falhas no uso" (E18).

“Todas as vezes que elas vêm, eu tenho por obrigação ver peso e pressão. Elas recebem até duas cartelas, três já fica muito distante" (E26).

"Eu quero vê-las todo mês e dificilmente entrego duas caixas" (E25).

"Prefiro não arriscar, pois pode ter má orientação, influência da vizinha” (E20).

A quantidade de anticoncepcional oral combinado estocada, por exemplo, era suficiente para entrega até trimestral em algumas equipes, entretanto, para a maioria, a quantidade era insuficiente até mesmo para entrega mensal (Diário de Campo). Duas enfermeiras confirmaram: "Até teria para três meses, mas elas [as usuárias] dão para as colegas" (E6). "Eu procuro não fazer isso, mesmo tendo a pílula porque todas vão querer receber da mesma maneira" (E12).

Outros 9 (31\%) enfermeiros se mostraram mais flexíveis à descentralização da entrega dos métodos anticoncepcionais, porém mantendo insegurança. Para estas, a entrega poderia ser facilitada em condições excepcionais, como: período chuvoso, localidades de acesso geográfico difícil, trabalhadores e usuárias já conhecidas da equipe.

"No inverno [período chuvoso] envio a pílula e a camisinha pelo agente de saúde. A auxiliar de enfermagemé orientada quanto a verificar a pressão, o peso, ouvir queixas e entregar a pílula na minha ausência, mas é raramente [justifica como se estivesse aplicando uma conduta incorreta]" (E3, grifo nosso).

“Acontece do auxiliar atender, mas é raro. $O$ retorno é mensal e dependendo da distância entrego até duas caixas" (E16, E24, E27).

“... A exceção é quando trabalham 40 horas. Quem eu já conheço me arrisco a entregar duas cartelas" (E10, E17).

"Às vezes, dependendo da mulher eu mando" (E21).

Menor resistência foi atribuída à entrega do condom masculino, quando se destacou: “... porém o condom, eu permito" (E13).

"Eu ia para uma localidade e não tinha carro. Fiz uma relação de quem usava camisinha e mandei pelo agente de saúde" (E23).

\section{$\underline{\text { Rede de serviço de planejamento familiar }}$}

Parte dos enfermeiros desconhecia a referência para a laqueadura tubária, vasectomia, inserção do DIU e seguimento de infertilidade. Alguns, apesar de conhecerem a referência desacreditavam do serviço em razão de experiências negativas, como o difícil acesso dos usuários, resposta inadequada ao caso e baixa resolubilidade:

"Encaminhei uma ligação. Era uma mulher com 28 anos e seis filhos e a direção do hospital ainda ficou pensando se fazia a ligação" (E6).

"A verdade é que o DIU não se coloca em (...) [referência]. O ginecologista só vai de 15 em 15 dias ..." (E23).

"Não tenho vontade de encaminhar nada, pois não tem solução” (E2).

Há na CERES um serviço de referência para laqueadura, um para inserção do DIU e nenhum para vasectomia (Diário de Campo). Os enfermeiros, por outro lado, atribuíram pouca importância ao fato, uma vez que esse tipo de demanda não era significativo.

Apesar de a inserção do DIU ser um procedimento plenamente praticável no nível primário da atenção, na CERES estudada não transcorria desta forma. Quatro dos oito municípios contavam com profissionais habilitados para realizar a inserção, mas faltava o DIU. Os demais reportavam-se, porém, ao fato de o serviço de referência só atender durante um dia por semana, o que tornava o acesso das mulheres bastante limitado (Diário de Campo).

Quanto aos casos de infertilidade, os enfermeiros apresentaram iniciativas distintas entre encaminhar para referência regional (15) - esta referência nem existia -, não saber para onde encaminhar (12), encaminhar para o médico da equipe (1) ou para unidade de alta complexidade por conta própria (1). O atendimento para estes casos não tinha sido pactuado por nenhum dos municípios da CERES, ou fora desta, e nenhum cuidado aos casais inférteis era oferecido no nível primário da atenção (Diário de Campo).

Quanto à utilização da própria comunidade ou de pontos comerciais como fonte de entrega de métodos anticoncepcionais, não foi encontrada nenhuma iniciativa. Os serviços são oferecidos durante atendimento específico de planejamento familiar, não tendo sido observada nenhuma tentativa de se estabelecer uma rede apropriada de serviços de planejamento familiar, por meio das maternidades e tipos outros de serviços de saúde reprodutiva. 


\section{Discussão}

Apesar da larga atuação do enfermeiro nas ações de planejamento familiar na CERES estudada, as equipes não dispunham de "rotina aprovada pela instituição de saúde”, requisito indispensável à prática legal do enfermeiro, conforme enunciado na "Lei do Exercício Profissional" (Lei no. 7.498), de 25 de junho de 1986, regulamentada pelo Decreto no. 94.406, de 8 de junho de 1987 12. No aspecto privativo de sua atuação e como integrante da equipe de saúde, no caso a equipe do PSF, referida lei determina que compete ao enfermeiro: "realizar a prescrição de medicamentos estabelecidos em programas de saúde pública e em rotina aprovada pela instituição de saúde" 13 (p. 17), ao que se inclui o planejamento familiar. Logo, para que o enfermeiro mantenha e amplie sua atuação no campo do planejamento familiar a seguir o princípio legal, necessário se faz elaborar "rotina de serviço". Nesse contexto, indaga-se: a quem compete preparar e aprovar a respectiva rotina? Essa é uma incógnita que inquieta as autoras, pois não encontraram parecer consensual por parte dos gestores, profissionais e órgão de classe, fato que destacam como ponto a ser definido pela categoria e pelo setor saúde.

Somente em quatro das 29 equipes de PSF acompanhadas, o médico respondia pela prescrição dos métodos anticoncepcionais. As razões para este desfecho foram: falta de médico na equipe de PSF, alta rotatividade destes mesmos nas equipes; cumprimento parcial da carga horária no PSF; pouco envolvimento deles nas atividades de planejamento familiar. Portanto, é o enfermeiro que assume a maior parte do atendimento em planejamento familiar, de sorte que, sem o amparo legal vivencia um dilema pela solicitação diária da comunidade que necessita do método. Destacam-se atitudes conflitantes por parte dos enfermeiros: aqueles que tomam da competência técnica e realizam prescrições, até corrigindo condutas médicas inadequadas, como a do caso em que fora prescrita a pílula para uma usuária de quarenta anos com hipertensão grave; e aquelas que entregam o método anticoncepcional sem formalizar a prescrição porque temem a uma denúncia. O que predominou, porém, foi a disponibilidade ou não do médico como fator determinante a prescrição de métodos anticoncepcionais pelos enfermeiros, desfecho inadmissível para a categoria profissional, pois considera-se que o enfermeiro exerça suas funções com independência e domínio técnicocientífico. Aliás, a função do enfermeiro não é de suprir lacunas médicas.

É preciso, pois, uma política nacional de planejamento familiar que reconheça o potencial do enfermeiro em manejar os métodos anticoncepcionais e explicite seu amparo legal para que assuma com autonomia essa área do cuidado para a qual soma grande contribuição.

No final dos anos 1970, as lutas em prol da saúde reprodutiva das mulheres encontraram fortes barreiras, destacando o Estado autoritário, que não atendia as necessidades básicas da maioria da população; a hegemonia biomédica na formulação de representações sobre o corpo feminino e o lugar social da mulher; e os programas verticais de planejamento familiar, implementados por organismos internacionais desde a década de 1960 14. O questionamento acerca do saber e do poder médico foi sempre motivo para discussão, pois este era caracterizado tanto como um saber disciplinador quanto um conhecimento que justificava a hierarquia entre os sexos. Uma enfermeira declarou: “aqui e nos outros postos, 'todos' aceitam a prescrição da enfermeira” (E7), quer dizer, o poder municipal aceita a prescrição de enfermagem, porém omite o respaldo para o exercício legal da profissão.

Hatcher et al. 15 ressaltam que uma variedade de pessoas pode informar sobre planejamento familiar e oferecer métodos anticoncepcionais. Em diversos países, além do médico, enfermeiros, auxiliares e técnicos de enfermagem, agentes de saúde, parteiras tradicionais, educadores, membros da comunidade e usuários experientes de métodos anticoncepcionais oferecem, habitualmente, serviços de planejamento familiar. Para tanto, é oferecida capacitação adequada, bem como são determinados os padrões a serem seguidos por quem oferece os métodos. Na visão desses autores, a pílula combinada, a pílula somente de progestágeno, o preservativo masculino, os espermaticidas, os métodos comportamentais e a amenorréia da lactação podem ser oferecidos por todos os que foram citados; os injetáveis, por qualquer pessoa treinada na aplicação; o diafragma, por qualquer provedor treinado para realizar exames pélvicos e medir seu tamanho; e o DIU pode ser inserido por médicos, enfermeiros e obstetrizes treinadas. Apesar de os autores não terem tratado sobre o preservativo feminino, acrescente-se que este método pode ser oferecido por qualquer uma das pessoas citadas e, principalmente, por usuárias experientes.

Em vista do exposto, sugere-se que o enfermeiro do PSF da CERES estudada e de outros serviços que venham corroborar essa discussão inclua o auxiliar de enfermagem, o ACS e o próprio usuário experiente, no atendimento em planejamento familiar, por meio de um processo de capacitação e educação continuada, o qual 
garanta a competência e a segurança a estes e aos clientes, superando o poder profissional que permeia a atenção nessa área do cuidado. Bruce ${ }^{5}$ reitera a noção de que os efeitos colaterais dos métodos anticoncepcionais modernos não são perigosos e que a participação de outras pessoas na divulgação e entrega dos serviços de planejamento familiar contribui para melhorar o acesso, a informação e a continuidade de uso.

A Figura 1 sintetiza a dinâmica de atendimento em planejamento familiar na CERES estudada.

Os enfermeiros levantaram preocupações desnecessárias que não justificam a oposição da entrega de métodos anticoncepcionais em intervalo mais longo. Quanto ao aspecto da usuária apresentar dúvidas, efeitos colaterais e/ou complicações e o método falhar, é importante determinar uma relação de co-responsabilidade com a usuária, vale dizer, que o enfermeiro ou a equipe de saúde a oriente adequadamente a fim de que ela use o método corretamente, bem como reconhecer sinais e sintomas relacionados ao uso e, assim, procurar o apoio da equipe quando necessário. Sobre a preocupação de verificar peso e pressão arterial das usuárias, mensalmente, não há evidência científica que justifique tal conduta. A respeito do temor com relação à possível influência da comunidade, hão de ser feitas ativida- des coletivas de esclarecimento sobre o planejamento familiar e os métodos anticoncepcionais, envolvendo famílias e a comunidade. Aliás, é a proposta do PSF trabalhar o indivíduo no contexto onde ele vive. As equipes de PSF devem transformar as comunidades em verdadeiras aliadas na promoção do planejamento familiar.

$\mathrm{O}$ atendimento oferecido produz descontentamento em parte dos usuários, que solicitaram mudanças, considerando inadmissível o retorno mensal para a entrega dos métodos anticoncepcionais, quando têm seus afazeres domésticos, trabalho formal, ter que pagar passagem ou caminhar horas até chegar à unidade de saúde. A esse respeito, estratégias de descentralização da entrega dos métodos anticoncepcionais com maior participação do auxiliar de enfermagem e dos ACS, bem como a parceria com pontos comerciais e outras instituições confiáveis que possam auxiliar, poderia fazer o método chegar mais perto de onde as famílias vivem, sem tantas barreiras. Essa é a proposta de uma rede apropriada de serviços de planejamento familiar.

Apesar de esta CERES dispor formalmente de uma referência para encaminhamento das mulheres que optarem pela laqueadura tubária, o acesso delas é difícil, em razão da baixa oferta de serviço e de barreiras técnicas que negam o procedimento. O impedimento técnico é um as-

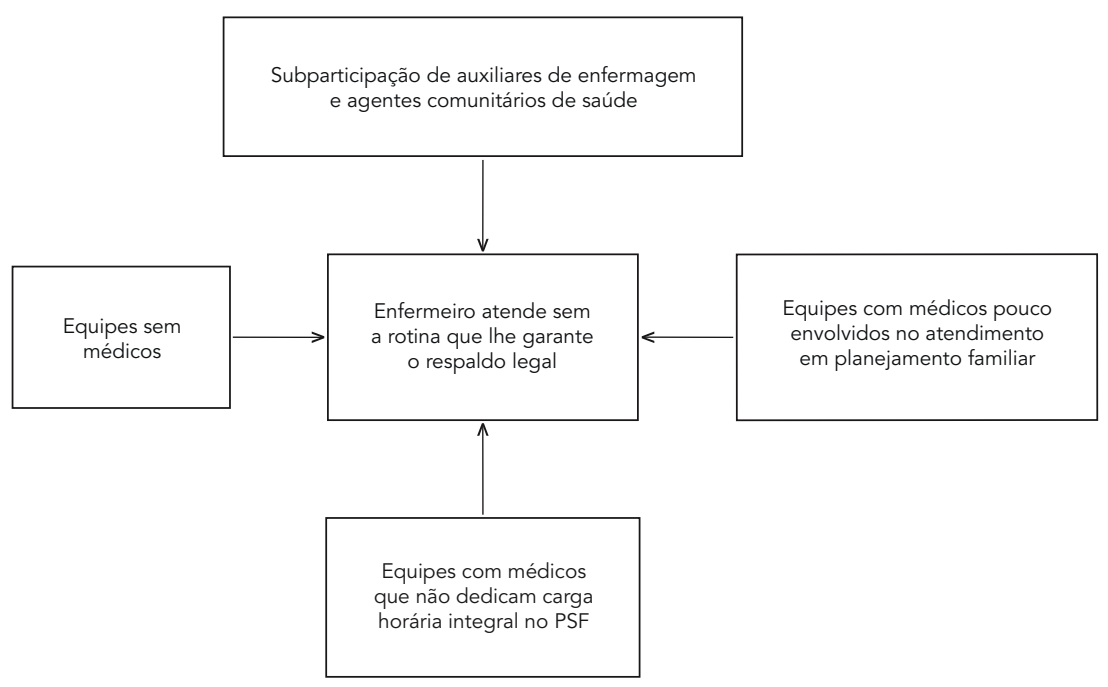


pecto denunciado em vários estudos que confirmaram a necessidade de treinamento e reciclagem de médicos e enfermeiros que lidam com o planejamento familiar no Brasil e no Ceará, em particular 16,17,18.

No campo da esterilização, as necessidades são pouco atendidas, pela baixa oferta de serviço e barreiras profissionais como a do caso relatado em que o serviço de referência levantou dúvidas para laquear uma usuária com 28 anos e seis filhos vivos, quando a lei do planejamento familiar assegura o procedimento para mulheres maiores de 25 anos ou, pelo menos, com dois filhos vivos 4 .

A vasectomia não é divulgada e, desse modo, não surge demanda. Marchi et al. 19 em estudo sobre a opção pela vasectomia, detectou no universo de vinte casais determinados a realizar a referida cirurgia que apenas dois haviam sido referidos por serviços de saúde, enquanto os demais foram indicados por amigos e pessoas da família, significativas para a tomada da respectiva decisão. Conseqüentemente, este estudo reforça a omissão dos serviços de saúde, marcadamente os de atenção primária, em oferecer informações e dar oportunidades a homens e casais de incluírem na relação de suas opções contraceptivas a vasectomia.

Evidencia-se uma situação crítica que poderia ser amenizada por meio de uma supervisão regional, envolvendo dois aspectos: primeiro, gerenciando a oferta de DIU nos municípios que dispõem de profissional habilitado para inserilo; segundo, promovendo a capacitação de médicos e enfermeiros para realizarem a inserção. Este treinamento poderia ser efetuado pelos próprios médicos da região, já treinados e inclusive atendendo a necessidade daquelas mulheres que aguardam por uma inserção. Este é um dos princípios da regionalização da saúde, proposto na NOAS/200120.

Os casos de infertilidade, não são acolhidos no PSF e são remotas as possibilidades de encaminhamentos para outros níveis de atenção, inclusive não há pactuação para a oferta desses cuidados. A atenção ao casal infértil deve ser tratada com o mesmo empenho da atenção aos casais férteis, justificando que o planejamento familiar inclui tanto as ações voltadas à concepção quanto aquelas tendentes à contracepção ${ }^{4}$. Destaca-se um trabalho realizado no Centro de Planejamento Natural da Família (CENPLAFAM) de Curitiba, no qual os profissionais aplicam o conhecimento dos métodos anticoncepcionais, incluindo o apoio psicológico, estimulando as mulheres à auto-observação, levando ao conhecimento do período fértil, do funcionamento do corpo, bem como das oscilações hormonais e repercussões na sexualidade. Tal método envolve mesmo aquelas(es) mulheres/casais com baixo grau de instrução formal. Portanto, trata-se de atividades simples de instrução para a obtenção de consciência corporal e autoconhecimento, que alcança êxito, pelos vários bebês nascidos em função do acompanhamento 21 .

Em conclusão, é sugerido que a dinâmica do atendimento em planejamento familiar no contexto do PSF seja redimensionada, de maneira a facilitar o acesso dos usuários aos métodos anticoncepcionais, promovendo maior participação do auxiliar de enfermagem e dos ACS nas ações e estabelecendo parcerias com várias instâncias da comunidade para funcionar como ponto de entrega de métodos. Também é relevante incorporar a perspectiva da integralidade das ações, que serviços outros de atenção à saúde ofereçam atenção em planejamento familiar. A resolução do impasse legal quanto à prescrição dos métodos anticoncepcionais merece uma tomada de decisão urgente, pois configura barreira da comunidade aos métodos e transtorno legal e ético ao profissional.

Por fim, sugere-se que ações de planejamento familiar no contexto do PSF rompam com o simples ato de entrega de anticoncepcionais e promovam relações familiares, comunitárias e sociais mais saudáveis, com espaços para conversarem e trocarem experiências sobre as condições de vida (sociais, econômicas, políticas), visando à participação comunitária e de todos os membros da equipe.

Estudos futuros devem ser formatados com objetivo de identificar dinâmicas outras no PSF que venham inovar a atenção ao planejamento familiar e esclarecer o dilema legal e ético da prescrição de métodos pelos enfermeiros. 


\section{Resumo}

Pesquisa avaliativa realizada em oito municípios do Ceará, Brasil, de julho a setembro de 2003. Os dados foram coletados por entrevistas realizadas com 29 enfermeiros e 50 usuárias do Programa Saúde da Família (PSF) e observações nas unidades de saúde. Teve por objetivos identificar a dinâmica do atendimento em planejamento familiar e verificar barreiras voltadas ao atendimento e entrega dos métodos anticoncepcionais, na perspectiva de uma rede apropriada de serviços. Identificaram-se cinco dinâmicas de atendimentos, porém nenhuma seguia uma rotina formal, o que ocasiona dilema legal e ético sobre a prescrição de métodos anticoncepcionais pelos enfermeiros; a entrega de métodos exige retorno mensal das usuárias, por determinações técnicas excedentes e desnecessárias que são barreiras ao acesso dos usuários aos métodos; e inexiste uma rede apropriada de serviços, com atendimento centralizado no enfermeiro e no médico, inexistindo parceria com serviços outros de saúde reprodutiva ou espaços comunitários. Estudos futuros devem ser formatados com vistas a identificar dinâmicas distintas no PSF que inovem a atenção ao planejamento familiar, bem como definir o aspecto legal e ético da prescrição de métodos pelos enfermeiros.

Planejamento Familiar; Anticoncepção; Programa Saúde da Família

\section{Referências}

1. Ministério da Saúde. Guia prático do Programa Saúde da Família. Brasília: Ministério da Saúde; 2001.

2. Ministério da Saúde. Saúde da família: uma estratégia para a reorientação do modelo assistencial. Brasília: Ministério da Saúde; 1998.

3. Secretaria Estadual de Saúde do Ceará. Sistema de informação da atenção básica. Fortaleza: Núcleo de Informação em Saúde, Secretaria Estadual de Saúde do Ceará; 2003.

4. Ministério da Saúde. Assistência em planejamento familiar: manual técnico. Brasília: Ministério da Saúde; 2002.

5. Bruce J. Fundamental elements of the quality of care: a simple framework. Stud Fam Plann 1990; 21:61-91.

\section{Colaboradores}

E. R. F. Moura participou da concepção do estudo, revisão de literatura, coleta de dados, análise e interpretação dos resultados do artigo. R. M. Silva colaborou na concepção metodológica, discussão e elaboração final do artigo. M. T. G. Galvão contribuiu na discussão e revisão final do artigo.

\section{Agradecimentos}

À equipe técnica da 4a Célula Regional de Saúde do Ceará, pelo apoio logístico à realização do estudo.
6. García-Núñez J. Avaliação em planejamento familiar: um guia para administradores e avaliadores. Salvador: Pathfinder Internacional; 1993.

7. Fonseca Neto MD, Vilar MCPM. Sistemas microrregionais de serviços de saúde: uma estratégia de reorganização do SUS - Ceará. Fortaleza: Secretaria Estadual de Saúde do Ceará; 2002.

8. Trentini M, Paim L. Pesquisa em enfermagem: uma modalidade convergente-assistencial. Florianópolis: Editora UFSC; 1999.

9. Cruz Neto O. O trabalho de campo como descoberta e criação. In: Minayo MCS, organizador. Pesquisa social: teoria, método e criatividade. Petrópolis: Editora Vozes; 1995. p. 51-66.

10. Triviños ANS. Introdução à pesquisa em ciências sociais. São Paulo: Editora Atlas; 1993. 
11. Bardin L. Análise de conteúdo. Lisboa: Edições 70; 1977.

12. Conselho Regional de Enfermagem do Ceará. Legislação 2001. Fortaleza: Conselho Regional de Enfermagem do Ceará; 2001.

13. Conselho Regional de Enfermagem do Ceará. Legislação. Fortaleza: Conselho Regional de Enfermagem do Ceará; 2001.

14. Ávila MB, Corrêa S. O movimento de saúde e direitos reprodutivos no Brasil: revisitando percursos. In: Galvão L, Díaz J, organizadores. Saúde sexual e reprodutiva no Brasil: dilemas e desafios. São Paulo: Editora Hucitec; 1999. p. 70-103.

15. Hatcher RA, Rinehart W, Blackburn R, Geller JS, Shelton JD. The essentials of contraceptive technology. Baltimore: The Johns Hopkins Bloomberg School of Public Health; 1997.

16. Diaz J, Diaz M. Contracepção na adolescência. In: Schor N, Mota MSFT, Branco VC, organizadores. Cadernos: juventude, saúde e desenvolvimento. Brasília: Ministério da Saúde; 1999. p. 249-57.
17. Moura ERF, Sousa RA. Educação em saúde reprodutiva: proposta ou realidade do programa saúde da família? Cad Saúde Pública 2002; 18:1809-11.

18. Moura ERF, Silva RM. Competência profissional e assistência em anticoncepção. Rev Saúde Pública 2005; 39:795-801.

19. Marchi NM, Alvarenga AT, Osis MJD, Bahamondes L. Opção pela vasectomia e relações de gênero. Cad Saúde Pública 2003; 19:1017-27.

20. Departamento de Descentralização da Gestão da Assistência, Secretaria de Assistência à Saúde, Ministério da Saúde. Regionalização da assistência à saúde: Norma Operacional da Assistência à Saúde: NOAS-SUS 01/02. 2a Ed. Brasília: Ministério da Saúde; 2002

21. Bertoldi A, Bertoldi ETS, Freitas MVSN. Ajudando casais a obterem uma gravidez: um projeto de humanização no Planejamento Familiar. Divulg Saúde Debate 2003; 26:37-40.

Recebido em 03/Mai/2006 Aprovado em 25/Set/2006 